\title{
Bronchial inflammation in acute bacterial exacerbations of chronic bronchitis: the role of leukotriene $\mathrm{B}_{\mathbf{4}}$
}

\author{
S.W. Crooks, D.L. Bayley, S.L. Hill, R.A. Stockley
}

\begin{abstract}
Bronchial inflammation in acute bacterial exacerbations of chronic bronchitis: the role of leukotriene B. S.W. Crooks, D.L. Bayley, S.L. Hill, R.A. Stockley. (C)ERS Journals Ltd 2000.

ABSTRACT: Neutrophils recruited to the airways in chronic obstructive pulmonary disease (COPD) are thought to mediate tissue destruction. Neutrophil recruitment is increased during bacterial exacerbations. The inflammatory process was studied in patients with an acute exacerbation of COPD in order to ascertain the role of leukotriene $\mathrm{B}_{4}\left(\mathrm{LTB}_{4}\right)$.

The sputum of eight subjects with a bacterial exacerbation of COPD was analysed for neutrophil products (myeloperoxidase, elastase) and chemoattractants (interleukin-8 (IL-8) and $\mathrm{LTB}_{4}$ ). The contribution of $\mathrm{LTB}_{4}$ to the chemotactic activity of the sputum sol phase was determined using the $\mathrm{LTB}_{4}$ receptor antagonist LY293111. The concentrations of the serum acute phase proteins $\alpha_{1}$-proteinase inhibitor, $\alpha_{1}$-antichymotrypsin and $C$-reactive protein were measured. All patients received appropriate broad-spectrum antibiotic treatment for 7-14 days.

Initially, the sputum myeloperoxidase activity was high, indicating neutrophil influx; this was associated with high levels of IL-8 and LTB $_{4}$. All these concentrations fell with treatment $(p<0.01)$. The chemotactic activity of the sputum was raised on presentation and fell with treatment $(p<0.01)$. $\mathbf{L T B}_{4}$ contributed $\sim 30 \%$ of the total chemotactic activity on presentation; this diminished with therapy. All acute phase proteins were raised on presentation and fell with therapy $(p<0.01)$.

These findings suggest that leukotriene $B_{4}$ contributes to neutrophil influx into the airway in chronic obstructive pulmonary disease and may influence disease progresgression.

Eur Respir J 2000; 15: 274-280.
\end{abstract}

Increased numbers of neutrophils are found in bronchial lavage samples [1] and bronchial wall biopsies [2] from subjects with chronic bronchitis (CB) even when they are clinically stable, and it has long been thought that neutrophil-mediated airway damage plays a central role in the pathogenesis of $\mathrm{CB}$ and related disorders [3]. Neutrophil recruitment to the airways in subjects with $\mathrm{CB}$ is likely to depend on several signalling molecules and their receptors, including the chemoattractants interleukin- 8 (IL-8) and leukotriene $\mathrm{B}_{4}\left(\mathrm{LTB}_{4}\right)[4,5]$. Since both of these chemoattractants are produced by activated neutrophils, they may thus amplify and prolong the inflammatory response [6].

These inflammatory signalling molecules may be more critical in the presence of an acute exacerbation of chronic obstructive pulmonary disease (COPD), particularly when bacteria are the cause. Such episodes are characterized by a positive bacterial culture and the presence of increased neutrophil recruitment [7]. However, not all exacerbations are bacterial in origin, which has led to confusion about the role of antibiotics and steroids in treatment, although both have been shown to play a role $[8,9]$. The nature of the acute inflammatory response during acute exacerbations of COPD has not been studied in detail and yet an understanding of the mechanisms will be critical in the development of rational and alternative or more effective therapeutic approaches.
Increased concentrations of IL- 8 have been found in the bronchial secretions of patients with COPD, and, furthermore, the levels of IL-8 correlate with myeloperoxidase (MPO), a biochemical marker for activated neutrophils [10], providing more direct evidence of its role in neutrophil migration. $\mathrm{LTB}_{4}$ is also found in the sputum of patients with CB [11], although little additional data is available and, in comparison to IL-8, the potential role of $\mathrm{LTB}_{4}$ in the generation of airway inflammation has been relatively neglected.

The present paper reports a study of a small group of well-defined COPD patients with a clear bacterial infective exacerbation of $\mathrm{CB}$ requiring hospital referral and antibiotic therapy. The aim was to assess some aspects of the inflammation in sputum and serum during the course of the exacerbation, until the patient had returned to the stable clinical state, with particular emphasis on the probable role of $\mathrm{LTB}_{4}$ in airway inflammation during these episodes.

\section{Subjects}

\section{Materials and methods}

Smokers or exsmokers with a primary diagnosis of COPD who had been referred to hospital with an acute exacerbation of $\mathrm{CB}$ were invited to participate. All had $\mathrm{CB}$, defined as daily sputum production for $\geq 3$ consecutive months in at least the previous 2 yrs [12]. An acute bacterial exacerbation was defined as an increase in dyspnoea 
and/or cough accompanied by an increase in sputum purulence, together with a positive bacterial sputum culture. In order to retain patient homogeneity, subjects were excluded from analysis if subsequent high-resolution computed tomography performed at the end of the study demonstrated the presence of bronchiectasis or lung function indicated significant reversible airflow obstruction. The protocol received ethical approval from the Local Research Ethical Committee and all subjects gave informed written consent prior to entry.

In addition, other subjects with stable COPD were assessed in order to determine the expected range of these sputum inflammatory markers. Finally in order to determine the variability of $\mathrm{LTB}_{4}$ concentration in sputum, a group of COPD patients were studied on five consecutive days when in the stable clinical state.

\section{Study design}

All subjects received appropriate broad-spectrum antibiotic treatment for 7-14 days, depending on confirmation of a clear clinical response (sputum becoming mucoid and symptoms improving). Bacterial culture was performed prior to antibiotic therapy, at the end of antibiotic therapy and when the subjects were clinically stable ( $\geq 2$ weeks after the end of antibiotic therapy). Sputum was collected for $4 \mathrm{~h}$ from wakening within $24 \mathrm{~h}$ of admission but before treatment was started (day 1) and then on days 3, 5, and 14, and, again, when clinically stable. Sputum samples were assessed visually for the presence of purulence and then centrifuged for $90 \mathrm{~min}$ at $50,000 \times g$ at $4^{\circ} \mathrm{C}$. The sol phase obtained was then divided into aliquots and stored at $-40^{\circ} \mathrm{C}$ until subsequent analysis. A venous blood sample was taken on each of these occasions, as well as an extra sample on day 7 , and allowed to clot and serum was separated and stored at $40^{\circ} \mathrm{C}$ until subsequent analysis.

All eight patients who fulfilled the clinical criteria outlined above provided samples of sputum at the start and end of treatment and when clinically stable. Six were able to provide adequate sputum samples at all time points during the study. Data from these six patients alone were used to determine the time-course of changes following the commencement of therapy.

\section{Methods}

Biochemical analysis. Sputum: MPO activity was used as a marker of sputum neutrophils [7], and measured by the colour released from the substrate $o$-dianisidine dihydrochloride (M6908; Sigma Chemical Company, Poole, UK) as described previously [13]. Samples from the same patient were analysed on the same plate and the same standard was used for all assays.

Elastase activity was measured in microtitre plates, as described previously [14], using $N$-succinyl-ala-ala-ala- $p$ nitroanilide (Sigma Chemical Company) as the substrate and pure neutrophil elastase of known activity as the standard. The lower limit of detection was $10 \mathrm{nM}$ and values less than this were treated as zero for statistical purposes.

IL-8 and $\mathrm{LTB}_{4}$ concentrations were measured by means of an enzyme-linked immunosorbent assay (ELISA) using commercial assay kits (D8050; Quantikine, Abingdon, UK and RPN223; Amersham International, Little Chalfont, UK, respectively). The between-batch coefficient of variation was $7.2 \%$ for IL-8 and $11.9 \%$ for LTB $_{4}$. Samples of sputum sol phase spiked with pure agent resulted in $>85 \%$ recovery on subsequent assay.

$\alpha_{1}$-Proteinase inhibitor concentrations in sputum sol phase samples were measured by means of an ELISA using a monoclonal antibody and serum standards (PC034; The Binding Site, Birmingham, UK). The ratio of $\alpha_{1}$-proteinase inhibitor $\left(\alpha_{1}-\mathrm{PI}\right)$ concentration in sputum sol phase to that in serum was used as a marker of airway inflammation (protein leak from blood to airway).

Chemotaxis assay. The chemotactic activity of the sputum sol phase (diluted 1 in 40) was assessed using a modified Boyden chamber technique [15] and neutrophils from healthy donors, with and without the inclusion of the $\mathrm{LTB}_{4}$ receptor antagonist, LY293111 sodium (Eli Lilly, Basingstoke, UK), characterized by others [16]. The 48-well microchemotaxis chamber used consisted of $27-\mu \mathrm{L}$ lower chambers containing the chemoattractant (sputum sol or $N$-formyl-methionyl-leucyl-phenylalinine (FMLP) or control solution and 50- $\mu$ l upper chambers containing neutrophils, separated by a $2-\mu \mathrm{m}$ pore polyvinylpyrrolidone-free polycarbonate filter (Costar Nucleopore; Costar, High Wycombe, UK). Neutrophils were isolated as described previously [13], resuspended in RPMI medium containing $0.2 \%$ bovine serum albumin and divided into two aliquots. LY293111 or control medium was added to the aliquots to give final concentrations of $1.5 \times 10^{6}$ neutrophils.mL $\mathrm{mL}^{-1}$ and $10^{-6} \mathrm{LM} \mathrm{LY293111}$ sodium. The concentration of LY293111 incubated with the neutrophils was in excess of that required to prevent neutrophil recruitment to $\mathrm{LTB}_{4}$ in the sputum sol phase [17]. Cells were incubated for $60 \mathrm{~min}$ at room temperature $\left(23^{\circ} \mathrm{C}\right)$ before being pipetted into the top wells of the assay chambers. Sputum samples collected at the start and end of antibiotic therapy, and samples taken when the patients were clinically stable, were assessed for chemotactic activity with neutrophils preincubated in the presence and absence of LY293111. FMLP was used as a positive control and RPMI medium/albumin as a negative control. Chemotaxis was allowed to occur for $20 \mathrm{~min}$ before removing, drying, fixing, and staining the membrane. The number of neutrophils that had migrated was obtained from five high-power $(\times 400)$ fields (HPFs) and the mean obtained. Three replicate wells were used for each sample assay and the mean of these replicates was taken as the result for the respective sample.

Serum. Serum C-reactive protein (CRP), $\alpha_{1}$-PI and $\alpha_{1}$ antichymotrypsin $\left(\alpha_{1}\right.$-ACP) were measured by means of radial immunodiffusion using commercial kits designed for this purpose (The Binding Site).

\section{Analysis}

Results were analysed using SPSS for Windows (SPSS, Inc., Chicago, IL, USA). Paired samples were compared using the Wilcoxon matched pairs test (single-tailed), and correlations made using Spearman's correlation coefficient. Differences between patients at the start and after the exacerbation were compared to the control patients using the Mann-Whitney U-test (single-tailed). Finally, the reproducibility of sputum $\mathrm{LTB}_{4}$ levels in the stable clinical state was confirmed by analysis of variance. All data are presented as mean \pm SEM. 


\section{Results}

\section{Patient demographics}

Eight patients (six male) were included, aged 56-73 yrs. Four were exsmokers and four current smokers, each having smoked for 35-140 pack-yrs (mean 68). The number of exacerbations treated with antibiotics in the previous 12 months ranged $0-10$ (mean 4.6) and patients had experienced increased symptoms for a mean of 12 days (range 2-28) before presentation at the hospital. None of the subjects were receiving antibiotics at the time of entry to the study, although four had been given a short course of oral antibiotic therapy within the previous month. Five patients were taking inhaled beclomethasone on presentation, which was continued at the same dose. Three of these five patients were also taking oral steroids (prednisolone) prior to presentation; prednisolone was continued in these three and started in one other who had been taking only inhaled steroids prior to admission. Three subjects received neither inhaled nor oral steroid treatment throughout the study.

\section{Lung function}

Lung function was measured $\geq 1$ month after clinical resolution of the exacerbation when subjects were clinically stable and the results are summarized in table 1 . All had severe airflow obstruction with $<15 \%$ reversibility to $\beta_{2}$-agonist (data not shown), air trapping and reduced gas transfer, consistent with the diagnosis of COPD and emphysema.

\section{Clinical response}

All patients were treated with an appropriate antibiotic and showed a good clinical response with resolution of their symptoms and a change in sputum appearance from purulent to mucoid.

Table 1. - Lung function of the exacerbation study patients of the chronic obstructive pulmonary disease controls when clinically stable

\begin{tabular}{lcc}
\hline & Patients & Controls \\
\hline Subjects n & 8 & 14 \\
FEV1 L & $0.65 \pm 0.09$ & $0.90 \pm 0.14$ \\
& $(27.9 \pm 3.8)$ & $(34.6 \pm 5.2)$ \\
FVC L & $1.90 \pm 0.10$ & $2.30 \pm 0.21$ \\
& $(63.8 \pm 6.3)$ & $(70.3 \pm 6.8)$ \\
RV L & $4.39 \pm 0.45$ & $3.90 \pm 0.29$ \\
& $(198 \pm 16)$ & $(169 \pm 12)$ \\
RV/TLC \% & $64 \pm 2.0$ & $57 \pm 2.2$ \\
& $(164 \pm 8)$ & $(151 \pm 7)$ \\
KCO mmol $\cdot \mathrm{min}^{-1} \cdot \mathrm{kPa}^{-1} \mathrm{~L}^{-1}$ & $0.96 \pm 0.11$ & $1.00 \pm 0.11$ \\
& $(55 \pm 7.0)$ & $(57 \pm 6.4)$ \\
\hline
\end{tabular}

Data are presented as mean \pm SEM with percentage of the predicted value in parentheses. All volumes are given corrected to body temperature and ambient pressure, and saturated with water vapour, and predicted values were calculated from published standards. [18]. FEV1: forced expiratory volume in one second; FVC: forced vital capacity; RV: residual volume; TLC: total lung capacity; $K \mathrm{CO}$ : carbon monoxide transfer coefficient. There was no significant difference for any measurement between the groups.

\section{Sputum bacteriology}

On presentation Haemophilus influenzae was isolated from the sputum of five patients, Streptococcus pneumoniae of two and Branhamella (Moraxella) catarrhalis of one. At the end of therapy, sputum from six of the patients contained only a scanty growth of mixed normal flora, although the other two remained colonized, one with $H$. influenzae, and the other with $B$. catarrhalis, despite the clinical response and change in sputum appearance from purulent to mucoid. When seen $\geq 2$ weeks after the end of treatment whilst still clinically stable, three patients yielded a mixed normal flora from sputum and four had a bacterial pathogen (two $H$. influenzae, one $S$. pneumoniae and one Pseudomonas aeruginosa) and one was unable to provide a sufficient sputum sample for culture (all of the sample was required for biochemical analysis). Again, despite the presence of a positive bacterial culture, these patients remained well with mucoid sputum and all biochemical marker concentrations were reduced (see data below).

\section{Sputum analysis}

Myeloperoxidase. The MPO activity in arbitrary units was $4.20 \pm 1.86 \mathrm{U} \cdot \mathrm{mL}^{-1}$ at the start of the exacerbation, fell to $0.26 \pm 0.10 \mathrm{U} \cdot \mathrm{mL}^{-1}$ by the end of therapy $(\mathrm{p}<0.01)$, and remained low $\left(0.39 \pm 0.16 \mathrm{U} \cdot \mathrm{mL}^{-1}\right)$ when the patients were clinically stable. The time-course of variation in MPO activity is shown in figure 1 for the six patients who produced samples at each visit. This shows that the MPO activity fell rapidly from the start of treatment, although this fall was not statistically significant until day $14(\mathrm{p}<0.02)$.

Elastase activity. Elastase activity was detected in the sputum of seven of the patients on presentation $(400 \pm$ $200 \mathrm{nM}$ ), consistent with neutrophil recruitment to the airways, as indicated by the increase in MPO activity. The activity subsequently fell, becoming undetectable by day 5 in all patients $(\mathrm{p}=0.022)$ and remaining undetectable thereafter.

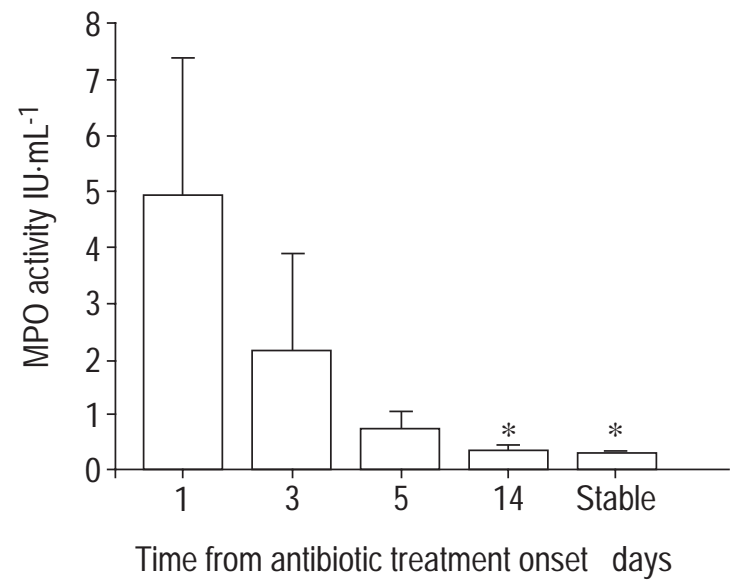

Fig. 1. - Sputum myeloperoxidase (MPO) concentrations in six patients from the onset of antibiotic treatment (day 1). Data are presented as mean \pm SEM. Stable: stable state after antibiotic treatment. ${ }^{+}: \mathrm{p}<0.02$ versus day 1 (on presentation). 
Interleukin- 8 . The IL-8 concentration in sputum was $24.0 \pm 4.8 \mathrm{nM}$ at the start of the exacerbation and fell to $8.8 \pm 2.4 \mathrm{nM}$ at the end of treatment $(\mathrm{p}<0.01)$ and $6.5 \pm$ $1.6 \mathrm{nM}$ when clinically stable $(\mathrm{p}<0.01$ versus start of exacerbation). The time course of this fall is summarized in figure $2 \mathrm{a}$, indicating that IL-8 fell to stable concentrations by the third day $(\mathrm{p}<0.02)$ and showed no alteration over the remaining period of the study.

Leukotriene $B_{4}$. The sputum $\mathrm{LTB}_{4}$ concentration was high when the patients presented with their exacerbation $(82.0 \pm$ $20.8 \mathrm{nM})$. By the end of treatment, the concentration had fallen significantly to $6.0 \pm 3.1 \mathrm{nM}(\mathrm{p}<0.01)$. However, there was a small but significant rise in levels from the end of treatment until the patients were reassessed when clinically stable $(10.2 \pm 4.5 \mathrm{nM} ; \mathrm{p}<0.01)$, although this value remained lower than that on presentation $(\mathrm{p}<0.01)$. The time-course of the fall in $\mathrm{LTB}_{4}$ concentration is shown in figure $2 \mathrm{~b}$ for the six patients who provided samples on each visit. The $\log _{10} \mathrm{LTB}_{4}$ concentration correlated well with the overall chemotactic activity of the sputum $(\mathrm{r}=0.76, \mathrm{p}<0.001)$.

Chemotactic activity. The negative control (cell culture medium) resulted in few cells passing to the lower chamber of the assay wells $\left(<5\right.$ cells.HPF $\left.{ }^{-1}\right)$, whereas the positive
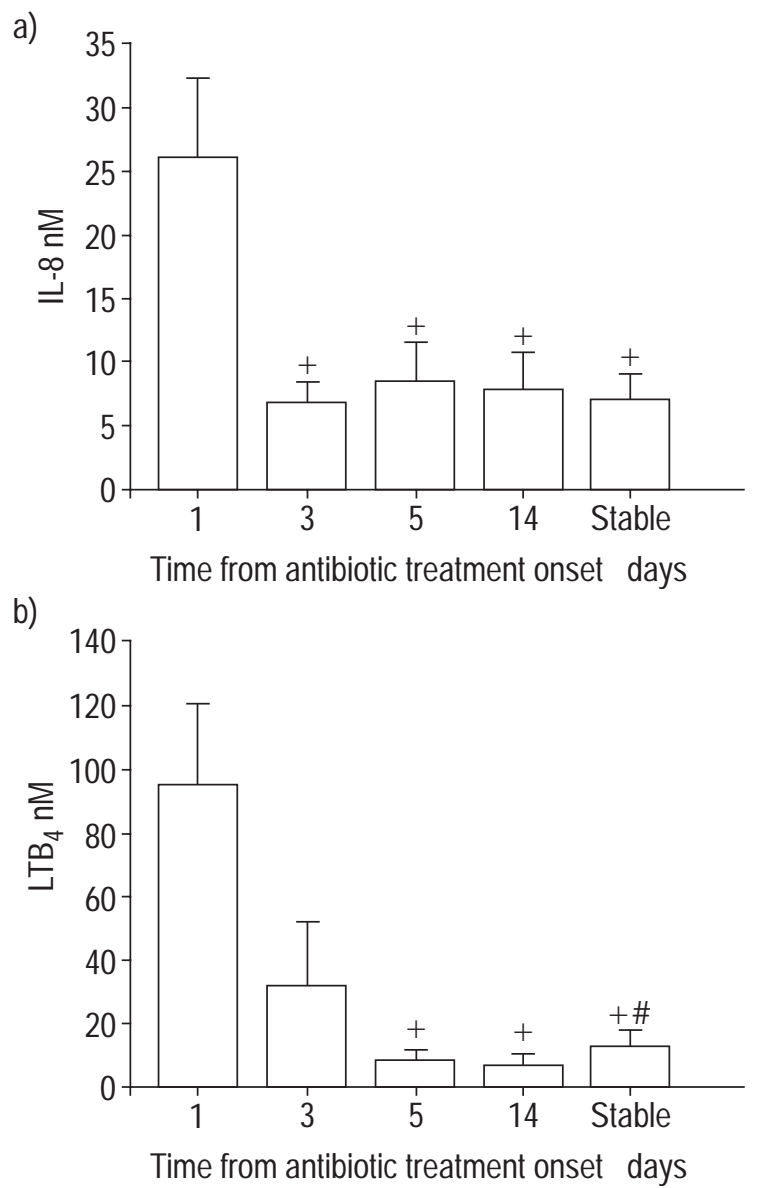

Fig. 2. - Sputum concentration of: a) interleukin-8 (IL-8); and b) leukotriene $\mathrm{B}_{4}\left(\mathrm{LTB}_{4}\right)$ from the onset of antibiotic treatment (day 1). Data are presented as mean $\pm \operatorname{SEM}(\mathrm{n}=6) .{ }^{+}: \mathrm{p}<0.02$ versus day 1 (on presentation); ${ }^{\#}: \mathrm{p}<0.02$ versus day 14 . control (FMLP) produced a good specific response (23.56 \pm 1.08$)$, which was undiminished by LY293111. These data and the results of the sputum chemotactic activity assay are summarized in figure 3 . Sputum chemotactic response amounted to $27.8 \pm 1.81$ cells $\cdot \mathrm{HPF}^{-1}$ on presentation and fell to $20.3 \pm 2.52$ by the end of therapy $(\mathrm{p}<0.01)$. There was no change between the end of therapy and when the patients were clinically stable $\left(20.5 \pm 1.56\right.$ cells $\left.\cdot \mathrm{HPF}^{-1}\right)$ The effect of the $\mathrm{LTB}_{4}$ receptor antagonist LY293111 was most marked on presentation with a $29 \%$ reduction in the chemotactic response to sputum to $19.7 \pm 1.51$ cells $\cdot \mathrm{HPF}^{-1}(\mathrm{p}<0.01)$. At the end of treatment, the addition of LY293111 reduced the chemotactic response to sputum by only $10 \%$ (NS). However, when the patients were reviewed (clinically stable) LY293111 reduced the chemotactic response by $20 \%$ to $16.2 \pm 1.74$ cells $\cdot \mathrm{HPF}^{-1}(\mathrm{p}<0.01)$. The contribution of $\mathrm{LTB}_{4}$ to chemotaxis, determined by subtracting the chemotactic response in the presence of LY293111 from that without the inhibitor for all sputum samples, showed a positive correlation with $\log _{10} \mathrm{LTB}_{4}(\mathrm{r}=0.69$, $\mathrm{p}<0.001)$. These results are summarized in figure 4 .

Sputum:serum $\alpha_{1}$-proteinase inhibitor. The sputum: serum ratio of $\alpha_{1}$-PI fell from $2.44 \pm 0.7$ on presentation to $0.85 \pm 0.27$ at the end of therapy $(\mathrm{p}<0.01)$ At follow-up, when the patients were clinically stable, the ratio had not altered from that at the end of treatment $(0.93 \pm 0.26)$. The time-course of the $\alpha_{1}$-PI sol:serum ratio is summarized in figure 5, which shows that values fell quickly to stable levels by the fifth day of antibiotic treatment $(\mathrm{p}<0.05)$.

\section{Acute phase response}

Serum CRP concentration was increased on presentation to $135 \pm 36.2 \mathrm{mg} \cdot \mathrm{L}^{-1}$. The value fell to $11.48 \pm 4.18 \mathrm{mg} \cdot \mathrm{L}^{-1}$ at the end of therapy $(p<0.01)$ and remained unaltered when the patients were reviewed in the stable clinical state. The time-course indicated that serum CRP levels had declined to a stable value by the seventh day (fig. 6). Similar results

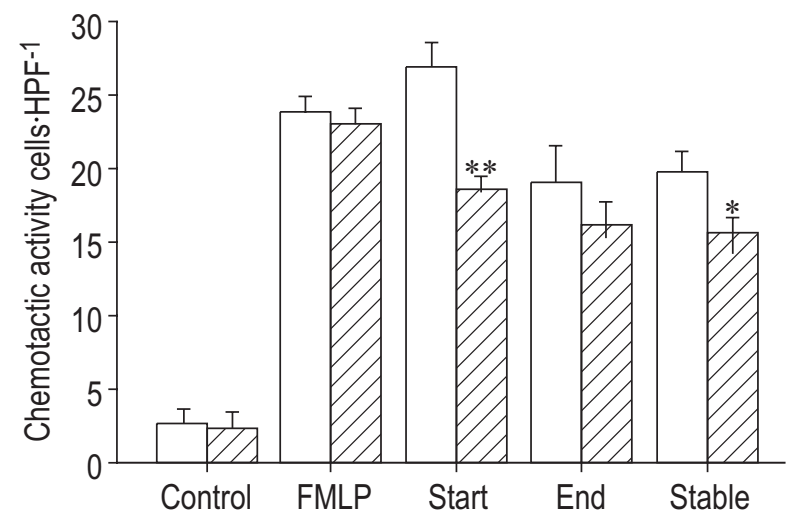

Fig. 3. - Chemotactic activity of the sputum sol phase (diluted 1 in 40) in the absence $(\square)$ and presence $(\mathscr{Z})$ of the leukotriene $B_{4}$ antagonist LY293111. Data are presented as mean \pm SEM $(n=8)$. HPF: high-power field; Control: cell culture medium alone; FMLP: $N$-formyl-methionylleucyl-phenylalanine $\left(10^{-8} \mathrm{M}\right.$; positive control); Start: on presentation; End: end of therapy; Stable: in the clinically stable state. ${ }^{* *}: \mathrm{p}<0.01$ versus chemotactic activity in the absence of LY293111. 


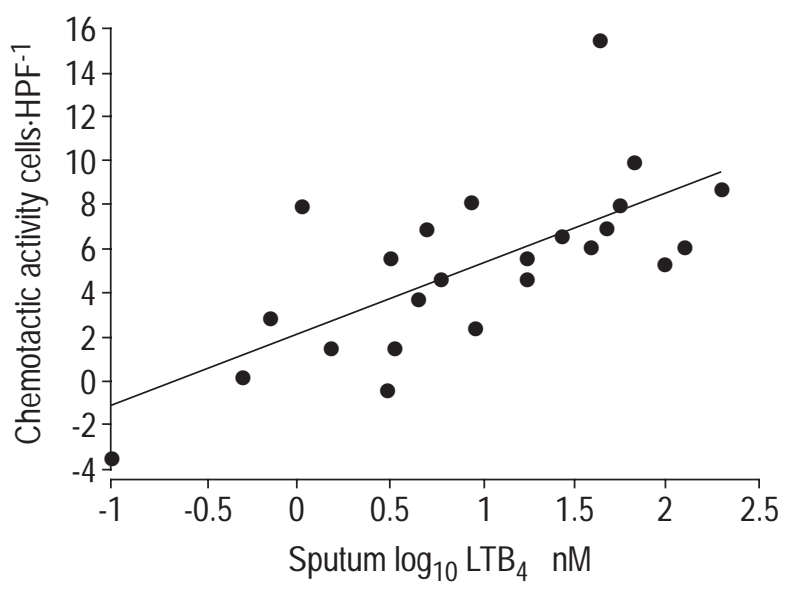

Fig. 4. - Contribution of leukotriene $\mathrm{B}_{4}$ at various concentrations to the chemotactic activity of sputum (derived from the difference in activities in the absence and presence of LY293111). Each point represents one sample. The regression line is shown $(r=0.69)$. HPF: high-power field.

were obtained for serum $\alpha_{1}$-PI and $\alpha_{1}$-ACP. The serum $\alpha_{1}$-PI concentration was $2.65 \pm 0.24 \mathrm{~g} \cdot \mathrm{L}^{-1}$ on presentation, fell to $2.15 \pm 0.19 \mathrm{~g} \cdot \mathrm{L}^{-1}$ at the end of treatment $(\mathrm{p}<0.025)$ and remained low $\left(2.03 \pm 0.22 \mathrm{~g} \cdot \mathrm{L}^{-1}\right)$ when the patients were clinically stable. The serum $\alpha_{1}$-ACP concentration was $1.39 \pm 0.24 \mathrm{~g} \cdot \mathrm{L}^{-1}$ on presentation, fell to $0.96 \pm 0.12$ $\mathrm{g} \cdot \mathrm{L}^{-1}$ at the end of treatment $(\mathrm{p}<0.02)$ and also remained low $\left(0.69 \pm 0.08 \mathrm{~g} \cdot \mathrm{L}^{-1}\right)$ when the patients were clinically stable.

\section{Comparison with control patients}

In order to determine whether the changes observed at the start of the exacerbation were a clear change from the stable state for patients with COPD and not related to the intrasubject variability described above, the present data were compared to a further control group of 14 patients studied only in the stable state. The control group had similar demographic data compared to the exacerbation group. Their ages ranged 44-79 yrs, four were exsmokers and 10 current smokers. Their lung function data are

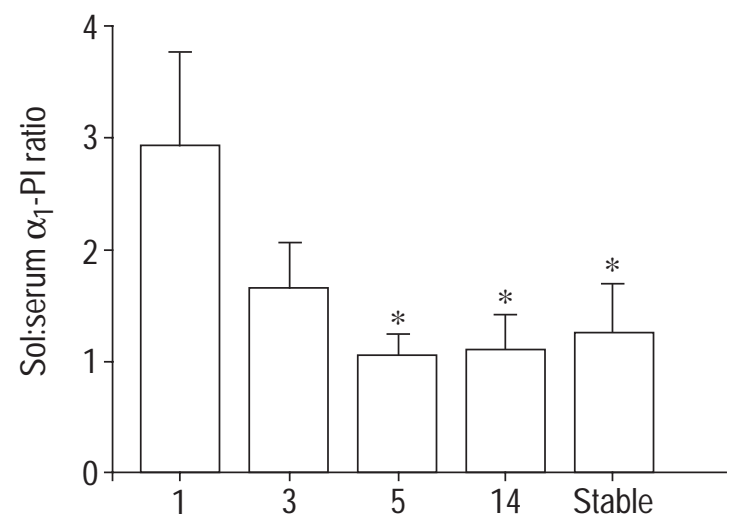

Time from antibiotic treatment onset days

Fig. 5. - Sputum sol phase:serum $\alpha_{1}$-proteinase inhibitor $\left(\alpha_{1}\right.$-PI) ratio from the onset of antibiotic treatment (day 1). Data are presented as mean $\pm \operatorname{SEM}(\mathrm{n}=6) .{ }^{*}: \mathrm{p}<0.05$ versus day 1 (on presentation). summarized in table 1. Sputum samples from the stable control group contained measurable quantities of MPO, IL-8, LTB $_{4}$ and $\alpha_{1}$-PI but no detectable elastase activity. The results are summarized in table 2 and confirm that the values obtained in the exacerbation group at the start of the exacerbation were greater than the control group for all parameters assessed. However, the results were comparable to those obtained in the control group when the patients had returned to the stable clinical state. The $\mathrm{LTB}_{4}$ concentrations in sputum from six of the stable control patients with COPD studied on five consecutive days are shown in table 3 . These show no significant day-to-day variation as a group $(\mathrm{p}>0.05)$.

\section{Discussion}

The nature and management of acute exacerbations of COPD is currently uncertain. In particular, antibiotic therapy is often used empirically and its role has therefore been questioned [19]. This view probably reflects imprecise definition of such episodes, which may be the clinical effect of many factors including increased airflow obstruction as well as viral or bacterial infection. The patients themselves are often heterogeneous and rarely defined in detail in clinical studies. In addition, even when a bacterial cause is identified, the aetiological agent varies as may the clinical response, even with standard therapy. For these reasons, selection of patients was carried out carefully in the present study to ensure that their exacerbation was likely to represent a bacterial infection and that all subjects had COPD alone. All subjects were unwell, having experienced increased symptoms for a mean of 12 days, and all had purulent sputum yielding a positive bacterial culture. This was associated with a marked systemic response with elevated CRP levels, and a lesser but still significant increase in the other acute phase proteins assayed, $\alpha_{1}$-PI and $\alpha_{1}$-ACP, confirming the severity of the episodes. Sputum studies indicated that the presence of bronchial inflammation was also markedly increased compared to the stable state (both in the patients studied and compared to a second group of stable patients with COPD), with increased MPO activity, confirming the pre-

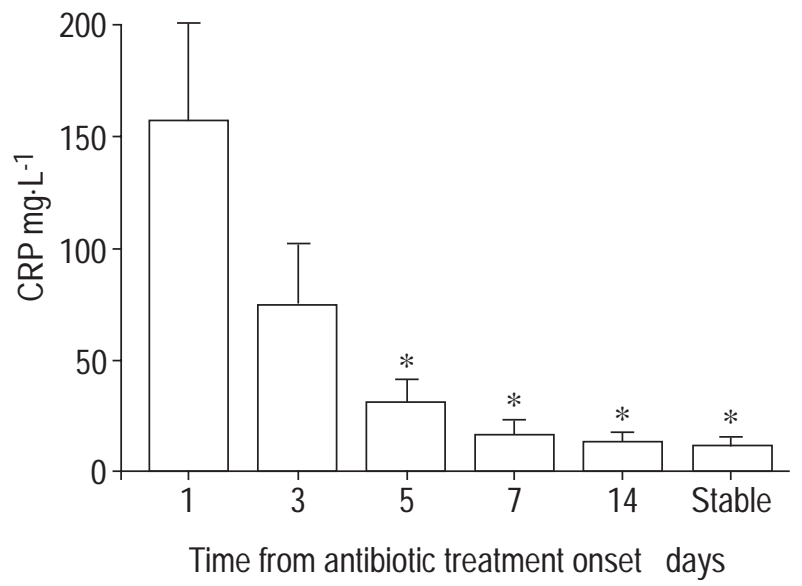

Fig. 6. - Acute phase response. Serum C-reactive protein (CRP) concentrations during the exacerbations of chronic bronchitis from the onset of antibiotic treatment (day 1). Data are presented as mean \pm SEM $(\mathrm{n}=6) .{ }^{*}: \mathrm{p}<0.05$ versus day 1 (on presentation). 
Table 2. - Biochemical analysis of sputum from the study patients at the start of treatment for an exacerbation and after the end of the exacerbation (stable state) compared with that of clinically stable control patients

\begin{tabular}{|c|c|c|c|c|}
\hline & Start of exacerbation & Stable state & Controls & p-value* \\
\hline Subjects $n$ & 8 & & 14 & \\
\hline MPO ICU $\cdot \mathrm{mL}^{-1}$ & $4.20 \pm 1.86$ & $0.39 \pm 0.16$ & $0.19 \pm 0.04$ & 0.0004 \\
\hline Elastase activity $\mathrm{nM}$ & $400 \pm 20$ & 0 & 0 & 0.0003 \\
\hline IL-8 nM & $24.0 \pm 4.8$ & $6.5 \pm 1.6$ & $8.3 \pm 1.9$ & 0.0031 \\
\hline $\mathrm{LTB}_{4} \mathrm{nM}$ & $82.0 \pm 20.8$ & $10.2 \pm 4.5$ & $10.6 \pm 3.0$ & 0.0001 \\
\hline$\alpha_{1}$-PI ratio (sol:serum) $\%$ & $2.44 \pm 0.7$ & $0.93 \pm 0.26$ & $0.96 \pm 0.37$ & 0.017 \\
\hline
\end{tabular}

Data are presented as mean \pm SEM. *: start of exacerbation versus stable control. MPO: myeloperoxidase; IL-8: interleukin-8; LTB 4 : leukotriene $\mathrm{B}_{4} ; \alpha_{1}$-PI: $\alpha_{1}$-proteinase inhibitor. There was no significant difference between the two groups in the stable state.

sence of significant neutrophil influx $[10,20]$. All these features would suggest that the exacerbation was both severe and associated with a neutrophil response characteristic of a bacterial infection.

Both of the chemoattractants, IL-8 and $\mathrm{LTB}_{4}$, were found in high concentrations on presentation and would be expected to provide the major drive to neutrophil influx. Previous studies have indicated that IL-8 is a major chemoattractant in airway secretions in the presence of bronchial disease [4]. However, the studies reported here (using an $\mathrm{LTB}_{4}$ receptor antagonist) indicate that $\mathrm{LTB}_{4}$ contributes $\sim 30 \%$ of the chemotactic drive in these samples during a bacterial exacerbation. This is consistent with recent findings in patients with bronchiectasis and COPD in the stable state [17], again emphasizing the importance of $\mathrm{LTB}_{4}$ in neutrophil responses to airway disease.

The sputum samples on presentation contained free elastase activity, which may play a significant role in the development and perpetuation of airways disease [3, 6]. In addition, significant airways leak of plasma proteins was present, as indicated by the high sputum:serum ratio of $\alpha_{1}$-PI. Both of these findings are consistent with earlier observations in patients with COPD studied as outpatients during exacerbations [21].

All patients remained on their current steroid therapy with the exception of one who received additional oral corticosteroids. However, all patients were started on appropriate new antibiotic therapy. The symptoms resolved in all patients accompanied by a reduction in bronchial inflammation as the sputum became mucoid. However, despite the rapid response to effective therapy, the presence of free elastase activity in the airways on presentation clearly represents a potential for airways damage. In particular, elastase can cause epithelial detachment [22] and damage to host mucociliary clearance [23]. Although there is no clear evidence that exacerbations of COPD are associated with a long-term decline in lung function [24, 25], it should be emphasized that the commonly applied definition of an exacerbation [8] does not require the inclusion of factors indicative of bacterial infection with neutrophil influx 16 and accompanying elastase release. It remains possible that more closely defined episodes, such as those reported in this study, contribute to airways disease and hence long-term morbidity. With this in mind it should be noted that the patients studied here had been unwell for 2-28 days prior to admission and commencement of appropriate treatment. Delay in the instigation of effective treatment may be of importance in determining disease progression and morbidity if elastase-induced damage plays a role. Further long-term studies are indicated to clarify this possibility; however, it seems reasonable that early appropriate treatment of purulent (and hence elastase-positive) exacerbations would be advisable.

IL-8 has been implicated in the pathophysiology of airway disorders including $\mathrm{CB}$ and bronchiectasis with or without cystic fibrosis $[4,6,10,17]$. The current study, in which high IL-8 concentrations were found, supports an important role for this neutrophil chemoattractant in the presence of acute infectious exacerbations of COPD, and IL-8 has been shown to contribute towards the chemotactic activity of sputum in several chronic conditions affecting the airways $[4,17]$. In contrast, the role of $\mathrm{LTB}_{4}$ has received little attention to date. The present findings suggest that $\mathrm{LTB}_{4}$ is also an important chemoattractant not only during acute exacerbations of COPD but also in the stable state. $\mathrm{LTB}_{4}$ concentrations are high in sputum at the beginning of an exacerbation and fall with effective treatment. However, following cessation of antibiotic therapy, $\mathrm{LTB}_{4}$ concentrations rise again, providing a lesser but significant chemoattractant drive that may, in part, account for the presence of neutrophils in lavage samples [1, 20], and in bronchial wall biopsies [2] from patients with COPD in a stable clinical state.

The source of the $\mathrm{LTB}_{4}$ is uncertain and may reflect contributions from resident macrophages and epithelial cells $[26,27]$ as well as activated neutrophils themselves [28]. The $\mathrm{LTB}_{4}$ concentrations correlated with both the overall chemotactic activity $(\mathrm{r}=0.76)$ and the contribution of $\mathrm{LTB}_{4}$ to the chemotactic activity, as assessed by its reduction in the presence of the specific $\mathrm{LTB}_{4}$ receptor antagonist $(\mathrm{r}=0.69)$. In addition, the concentration of $\mathrm{LTB}_{4}$ measured in the sputum sol phase was similar to that which induces neutrophil recruitment in the airways of healthy human volunteers [29]. A recent review has suggested that modulation of neutrophil recruitment to the lungs of patients with COPD is a potential strategy for modifying the natural history of the disease [30]. The data presented here suggests that $\mathrm{LTB}_{4}$ would be a viable target for such an approach both during infective exacerbations and in the stable clinical state, and agents which inhibit the production or actions of $\mathrm{LTB}_{4}$ would be expected to reduce neutrophil influx to the airway and consequently the potentially damaging effects of neutrophil elastase [3].

In conclusion, this study has shown an increase in the concentrations of the chemoattractants leukotriene $\mathrm{B}_{4}$ and interleukin-8 during infective exacerbations of chronic bronchitis in parallel with increased chemotactic activity, myeloperoxidase and elastase activity, and airways protein leak and a marked acute phase response. Leukotriene $B_{4}$ 
contributed significantly to sputum chemotactic activity both at the start of an exacerbation and when the patients were clinically stable. These data are consistent with a role for both leukotriene $\mathrm{B}_{4}$ and interleukin- 8 in the inflammation of chronic obstructive pulmonary disease, and intervention studies with appropriate antagonists may prove beneficial for patients with chronic bronchitis and related disorders by reducing the number, severity or length of acute bacterial exacerbations.

\begin{abstract}
Acknowledgements. The authors would like to thank C.G. Llewellyn-Jones for advice on methodology and criticism of the manuscript, and M.M. Johnson, J. Mitchell, A. Pye and K. Alton for performing bacterial culture on the samples.
\end{abstract}

\section{References}

1. Thompson AB, Daughton D, Robbins RA, Ghafouri MA, Oehlerking M, Rennard SI. Intraluminal airway inflammation in chronic bronchitis: characterisation and correlation with clinical parameters. Am Rev Respir Dis 1989; 140: 1527-1537.

2. Saetta M, Turato G, Facchini FM, et al. Inflammatory cells in the bronchial glands of smokers with chronic bronchitis. Am J Respir Crit Care Med 1997; 156: 16331639.

3. Stockley RA. The pathogenesis of chronic obstructive lung diseases: implications for therapy. QJM 1995; 88: 141-146.

4. Richman-Eisenstat JB, Jorens PG, Hebert CA, Ueki I, Nadel JA. Interleukin-8: an important chemoattractant in sputum of patients with chronic inflammatory diseases. Am J Physiol 1993; 264: L413-L418.

5. Crooks SW, Stockley RA. Leukotriene B4. Int J Biochem Cell Biol 1998; 30: 173-178.

6. Stockley RA. Role of bacteria in the pathogenesis and progression of acute and chronic lung infection. Thorax 1998; 53: 58-62.

7. Murphy TF, Sethi S. Bacterial infection in chronic obstructive pulmonary disease. Am Rev Respir Dis 1992; 142: 1067-1063.

8. Anthonisen NR, Manfreda J, Waren CPW, et al. Antibiotic therapy in exacerbations of chronic obstructive pulmonary disease. Ann Intern Med 1987; 106: 196-204.

9. Thompson WH, Nielson CP, Carvalho P, Charan NB, Crowley JJ. Controlled trial of oral prednisolone in outpatients with acute COPD exacerbation. Am J Respir Crit Care Med 1996; 154: 407-412.

10. Nocker RE, Schoonbrood DF, van de Graaf EA, et al. Interleukin-8 in airway inflammation in patients with asthma and chronic obstructive pulmonary disease. Int Arch Allergy Immunol 1996; 109: 183-191.

11. O'Driscoll BRC, Cromwell O, Kay AB. Sputum leukotrienes in obstructive airway diseases. Clin Exp Immunol 1984; 55: 397-404.

12. Medical Research Council. Definition and classification of chronic bronchitis for clinical and epidemiological purposes. Lancet 1965; i: 775-779.

13. Llewellyn-Jones CG, Harris TAJ, Stockley RA. The effect of fluticasone propionate on sputum of patients of patients with chronic bronchitis and emphysema. Am J Respir Crit Care Med 1996; 153: 616-621.

14. Morrison HM, Kramps JA, Afford CS, Burnett D, Stockley RA. The effect of assay condition on the measurement of anti-elastase function in lung secretions. Clin Chim Acta 1987; 162: 165-17.

15. Falk W, Goodwin RH Jr., Leonard EJ. A 48-well microchemotaxis assembly for rapid and accurate measurement of leukocyte migration. J Immunol Methods 1980; 33: 239-247.

16. Marder P, Sawyer JS, Froelich LL, Mann LL, Spaethe SM. Blockade of human neutrophil activation by 2-[2propyl -3 - [3- [2-ethyl-4-(4-fluorophenyl)-5hydroxyphenoxy]propoxy]phenoxy]benzoic acid (LY293111), a novel leukotriene B4 receptor antagonist. Biochem Pharmacol 1995; 49: 1683-1690.

17. Mikami M, Llewellyn-Jones CG, Bayley D, Hill SL, Stockley RA. The chemotactic activity of sputum from patients with bronchiectasis. Am J Respir Crit Care Med 1998; 157: 723-728.

18. Anonymous. Guidelines for the measurement of respiratory function. Respir Med 1994; 88: 165-194.

19. Anonymous. Antibiotics for exacerbations of chronic bronchitis. Lancet 1987; ii: 23.

20. Riise GC, Ahlstedt S, Larsson S, et al. Bronchial inflammation in chronic bronchitis assessed by measurement of cell products in bronchial lavage fluid. Thorax 1995; 50: 360-365.

21. Stockley RA, Burnett D. Alpha-1-antitrypsin and leukocyte elastase in infected and noninfected sputum. Am Rev Respir Dis 1979; 120: 1081-1086.

22. Amitani R, Wilson R, Rutman R, et al. Effects of human neutrophil elastase and Pseudomonas aeruginosa proteinases on human respiratory epithelium. Am J Respir Cell Mol Biol 1991; 4: 26-32.

23. Stockley RA. Bronchiectasis - new therapeutic approaches based on pathogenesis. Clin Chest Med 1987; 8: 481-494.

24. Kanner RE, Renzetti AD Jr., Klauber MR, Smith CB, Golden CA. Variables associated with changes in spirometry in patients with obstructive lung diseases. $A m J$ Med 1979; 67: 44-50.

25. Bates DV. The fate of the chronic bronchitic: a report of the ten year follow up in the Canadian Department of Veteran's Affairs coordinated study in chronic bronchitis. Am Rev Respir Dis 1973; 108: 1043-1065.

26. Fels AOS, Pawlowski NA, Cramer EB, King TCK, Cohn ZA, Scott WA. Human alveolar macrophages produce leukotriene B4. Proc Natl Acad Sci USA 1982; 79: 78667870.

27. Bigby TD, Lee DM, Meslier N, Gruenert DC. Leukotriene A4 hydrolase activity of human airway epithelial cells. Biochem Biophys Res Commun 1989; 164: 1-7.

28. Borgeat P, Krump E, Palmantier R, et al. The synthesis of leukotrienes by the human neutrophil. In: Holgate S, Dahlen S-E, eds. SRS-A to Leukotrienes. Oxford, Blackwell. 1997; pp. 69-84.

29. Martin TR, Pistorese BP, Chi KY, Goodman RB, Mathay MA. Effect of leukotriene B4 on the human lung. Recruitment of proteins into the alveolar spaces without a change in protein permeability. JClin Invest 1989; 84: 1609-1619.

30. Barnes PJ. New therapies for chronic obstructive pulmonary disease. Thorax 1998; 53: 137-147. 